\title{
CLARICE LISPECTOR: NARRACIÓN, CUERPO Y DESEO
}

Roberto Vincenti*

\section{RESUMEN}

La narrativa de Clarice Lispector despliega nuevas representaciones del cuerpo y el deseo femenino ante una modernidad amenazante. Su prosa revela en las grietas de lo cotidiano el instante fugaz que redime la existencia.

Palabras claves: Clarice Lispector. Deseo. Grietas. Existencia.

\section{THE DESIRE DURING MODERNITY}

\begin{abstract}
Clarice Lispector's narration shaws new representations of woman's body and desire against a threatenning modernity. Her prose reveals in the daily fissure the instant wich redeems the existence.
\end{abstract}

Keywords: Clarice Lispector. Desire. Fissure. Existence.

* Roberto Vincenti es Licenciado en Letras de la Universidad de Buenos Aires. Estudió cine en el Instituto Nacional de Cine y Arte Audiovisuales y dicta cursos sobre literatura y corrientes literarias en Institutos Terciarios de la ciudad de Buenos Aires. Participó en congresos y jornadas nacionales. Actualmente cursa la Maestría en literatura Latinoamericana y Española de la UBA. E-mail: robertovicenti@hotmail.com 


\section{Introducción}

Clarice Lispector despliega en su novela La hora de la estrella y en sus cuentos "Devaneo y embriaguez de una muchacha" y "Desespero e desenlance às tres da tarde" el proceso de construcción de una escritura que cuestiona los modos de representación tradicional y que elabora con sus tonos, sus monólogos interiores, sus ritmos, sus silencios, una representación de la experiencia y la percepción urbana. Así, su propuesta destaca que la renovación técnica y la experimentación no son contradictorias con el interés narrativo.

Además, como señala Andrade (1998, p.112), su obra supone una indagación sobre las diferentes facetas del cuerpo en la modernidad, donde proliferan lo biológico, lo gastronómico, lo erótico. Y en esta línea su escritura es suma y cifra del cuerpo de la mujer con sus vulnerabilidades, sus anhelos, sus vivencias intimas proponiendo una visión instropectiva que se ofrece en tensión con el vértigo que propone la metrópolis. Esta escisión entre la condición humana y el mundo admite sin embargo una singular poética del deseo representando existencias originales que transcurren entre el tedio y la persecución del instante creativo.

Por ello, los textos de Lispector resultan inquietantes, desestabilizadores, inacabados pues ejercitan una entropía mediante "enunciados que se alimentan de sí mismos" involucrando al lector en relación especular e invitándolo a leer en entrelíneas pues condensan la incomunicación que azota el escenario moderno.

\section{El autor}

El autor es una construcción teórica que tradicionalmente ha sido pensada como el depositario de los orígenes y sentidos de un texto. Críticos como Roland Barthes y Michel Foucault han puesto en tela de juicio esta visión canónica. En este sentido, cuando Barthes (1987) decreta metafóricamente la muerte del autor esta expresando las limitaciones de una figura vinculada a la estética romántica y considerada como genio o creador. Lo que esta en juego entonces es la imposibilidad de adjudicar sentidos unívocos a una obra literaria.

Foucault retoma con más precisión esta critica y determina la noción de autor como función cultural que se instala en el discurso. Dicha función está consagrada por 
mecanismos sociales, y legales, que determinan el proceso de la escritura. Está ligada al sistema jurídico e institucional que articula el universo de los discursos y no se ejerce de modo uniforme en todas las épocas.

Así señala Foucault: "no remite pura y simplemente a un individuo real, pude dar lugar a varios egos de manera simultanea a varias posiciones - sujeto que pueden ocupar diferentes clases de individuos." 1

Bajo este enfoque, el autor representa una de las tantas posibilidades del discurso: En este sentido en la novela La hora de la estrella, Rodrigo SM opera como una construcción ficticia. De este modo uno de los aspectos más notables es el manejo de esa función que instala el tópico de la creación dentro del relato porque Lispector crea un personaje que a su vez crea otro personaje produciendo un juego de tensiones e instaurando múltiples perspectivas en el texto.

El texto se ofrece como autoreferencial, la ficción reflexiona sobre su propia constitución y articula alusiones directas al lector donde se plasman las estrategias narrativas. Así, resulta una constante en el relato que Rodrigo alude en su transcurso a enunciados que tengan que ver con la materialidad de la escritura: "Como voy a decir ahora este relato será el resultado de una visión gradual." ${ }^{2}$

El narrador exhibe su propio dispositivo ficcional y también narra sus vivencias. En consecuencia el texto brinda la puesta en escena de una doble temporalidad que problematiza verdad y ficción pues se advierte la vacilación entre el acto de escribir sometido a cuestionamientos y postergaciones y el acto de reproducir el mundo.

Esas marcas desbaratan el desarrollo de una narrativa lineal ya que conducen el texto hacia otros planos paralelos. Rodrigo nos describe con singular morosidad sus pensamientos, peripecias y divagaciones. Obran en este sentido, las imágenes de su amante, su posición social, su dolor de muelas. El extrañamiento que propone la descripción de estos elementos conforma una trama paralela al proceso de gestación de Macabea.

Podría decirse que esta propuesta narrativa opera mediante asociaciones libres ("rezaba"), analogías (se compara el acto de escribir con el trabajo de un carpintero),

\footnotetext{
${ }^{1}$ FOUCAULT, 2002, p. 29.

${ }^{2}$ LISPECTOR, 2000, p. 14.
} 
sonidos (la música determina el ritmo del relato), digresiones (alusión a la bebida cocacola) visiones premonitorias (“explosión”).

Además, el narrador realiza en sus monólogos interiores persistentes apelaciones al lector involucrándolo, incluso puede leerse un protocolo de lectura que se va diseminando a lo largo de la novela. Dicho procedimiento resulta constante y se verifica de modo evidente tras la muerte de Macabea. En esta línea podemos pensar tal como señala Benjamín en su texto El autor como productor, que el lector se transforma en un "perito" que a la manera de un experto produce "tests" sobre lo observado. Así, la entidad de la escritura se constituye por la significación que el otro le concede.

Por otra parte, resulta significativa la decisión de utilizar un hombre como portavoz. Es posible interpretar que Lispector pretenda usar el fracaso del narrador para desintegrarlo y crear una disonancia con el lector poniendo en crisis tanto al hombre como poseedor exclusivo de la mirada coma a la mujer devenida en mera imagen. Así, Rodrigo menciona al comienzo de la novela, en gesto elocuente, que una mujer no pude describir la historia de Macabea: "Además - y lo descubro ahora -yo tampoco hago la menor falta hasta lo que escribo lo podría escribir otro. Otro escritor sí, pero tenía que ser hombre porque una mujer puede lagrimear tonterías."3

Según la lectura de Jean Franco, la novela presenta una reflexión sobre el excesivo poder autoral masculino que se destaca en forma evidente:

[...] al insistir en la actitud condesciende del narrador hacia su material se plantea el problema ético de la relación desigual que permite al escritor utilizar a la muchacha como materia prima y al mismo tiempo representar ese problema como si fuera una cuestión meramente estética. ${ }^{4}$

En este sentido, pude leerse en la figura del narrador la representación de una sociedad que no puede comprender al otro, al marginado y que por ello intenta el control a través del lenguaje. Y en esta línea, la adaptación fílmica de Suzana Amaral propone la ausencia del narrador privilegiando en la representación de Macabea reflexiones sobre la inmigración, la marginalidad y la discriminación sexual.

\section{Imágenes en la ciudad}

\footnotetext{
${ }^{3}$ LISPECTOR, 2000, p. 15.

${ }^{4}$ FRANCO, 1996, p. 106.
} 
Clarice Lispector refleja en su obra La hora de la estrella los efectos del nomadismo urbano y sus consecuencias en la vida social. El texto aborda el tópico de la joven provinciana que llega a la metrópolis en la búsqueda de fortuna y en procura de evasión de la monotonía rural.

El escenario moderno propone un sinnúmero de imágenes cuyo efecto ha sido examinado por Benjamín en su ensayo "La obra de arte en la época de su reproductibilidad técnica".

El autor analiza allí las consecuencias que sobre el plano de la percepción produce el dispositivo de reproducción tecnológica partir del desarrollo de la litografía y esencialmente de la fotografía la reproducción técnica propone una puesta masiva y cotidiana del arte en el mercado. Dicho dispositivo genera la atrofia del "aura" es decir la desaparición de la singularidad de la obra de arte marcando el pasaje del valor "actual" al valor "exhibitivo" y estableciendo diferentes percepciones de los objetos tornándolos mas cercanos a los sujetos pero también mas efímeros y uniformes. Así opera una dinámica de la apropiación que resulta simultanea a una recurrencia de "lo igual en el mundo".

En La hora de la estrella, el narrador concibe a Macabea a través de fotos que se suceden instaurando un mundo reproductivo dotado de una visibilidad exasperante, en donde se destaca el uso de la fotografía para capturar el instante de la relación con el otro.

Por eso Macabea resulta fascinada ante ese dispositivo de reproducción: "Al comenzar la relación había pedido a Olimpico una foto de 3 X 4 en la que él salía riendo para mostrar su canino de oro y ella se excitaba tanto que rezaba tres padrenuestros y dos aves marías para calmarse." 5

Por otra parte el cine inaugura una nueva modalidad de percepción colectiva que afecta a los individuos pues establece puntos de fuga y ensoñación y se convierte en enfermedad y remedio de la fugacidad que experimenta el sujeto moderno.

Benjamín capta como pocos esa instancia liberadora que propone el cine a través del "efecto de choque" que genera imágenes en movimiento: "Parecía que nuestros bares, nuestras oficinas, nuestra viviendas amuebladas, nuestras estaciones y

\footnotetext{
${ }^{5}$ LISPECTOR, 2000, p. 58.
} 
fábricas nos aprisionaban sin esperanza. Entonces vino el cine y con la dinamita de sus décimas de segundos hizo estallar ese mundo carcelario."6

En este sentido, La hora de la estrella trabaja en dos direcciones, el espectador de cine como receptor del hecho artístico y también como portador de un canon estético encarnado en el Star System. Las actrices despliegan su presencia en la pantalla y en la narración en la medida que desarrollan un complejo proceso de identificación en el que sirven de modelo a la experiencia. En consecuencia existe toda una operación teológica destinada a privilegiar el valor material de la mirada y el valor material del cine. Representación exacta del universo de los poseídos: creer en lo que se ve, desear lo que se ve. En la novela Macabea consuma ese ritual moderno pues acude una vez por mes al cine. $\mathrm{Y}$ en lo esencial exhibe una devoción enfermiza hacia las grandes estrellas de Hollywood: Marilyn Monroe y Greta Garbo.

La inolvidable y siempre perenne Marilyn constituye un fetiche pertinaz en el texto pues su figura instala connotaciones perturbadoras tanto como icono de la cultura de masas como también oscuro objeto del deseo .

La idealización de su belleza constituye una completud inalcanzable. Se pude inferir que Marilyn es el enunciado que permite indagar sobre la continuidad arte - vida y porque su presencia usurpa todos los sentidos de Macabea.

El intento de emulación se propone hasta la exasperación y expone de qué manera la cultura de masas educa los sentimientos, influye sobre las conductas y determina los modos de vida: "en el servicio de la oficina se pintó la boca y hasta fuera del contorno para que sus labios finos tuvieran ese aspecto tan bonito como los labios de Marilyn Monroe."7

Ahora bien, que significa cultura para Macabea?

Esa relación está determinada en el texto por las propuestas que elabora la industria pues el cine y la radio legitiman con sus discursos las funciones sociales de los productos. El poder y la intensidad de estos medios repercuten en lenguaje. Por eso la protagonista esta involucrada en una dinámica que propone "vocabulario" nuevo y que además exacerba la sensibilidad: la mención a la voz de Caruso resulta antológica. Así, la protagonista está inmersa en una cultura de masas que provoca emociones extremas y situaciones dramáticas por ello el narrador alude al final del texto al melodrama que

\footnotetext{
${ }^{6}$ BENJAMIN, 1982, p. 47.

${ }^{7}$ Ibid., 1982, p. 59.
} 
supone la vida de Macabea e ironiza sobre su muerte adjudicándole el mote de estrella de cine.

Si bien se mira, la muerte de Macabea puede ser leída como el cumplimiento de un destino. Y en lo esencial resulta un castigo por su bovarismo pues la persecución de esa esfinge (Marilyn) consumida por las masas termina devorándola.

\section{Cuerpo, hastío y deseo}

Lacan describió de que modo el instante en que el niño reconoce su propia imagen resulta esencial para la constitución del sujeto pues la fase del espejo instala un reconocimiento que supera a la experiencia del propio cuerpo. Así, surge la prolongada y amorosa relación de atracción y repulsión entre imagen y autoimagen. Este proceso crea la base para todas las identificaciones posteriores y encuentra intensa expresión en los textos de Clarice Lispector.

Tradicionalmente concebido como un símbolo de la vanidad de la mujer, en su obra alcanza amplias significaciones. Sus personajes se miran constantemente en el espejo y a través de su reflejo se conocen o se autoengañan confirman su identidad y su belleza.

Ellos en la medida que se observan en el espejo descubren facetas inéditas, en la medida que miran al otro visto como espejo de uno mismo, se crean a sí mismos.

La protagonista de "Devaneo y embriaguez de una muchacha" abre el relato ejerciendo un prolongado ritual ante el espejo. La fascinación por su imagen persigue la búsqueda del yo: "Los ojos no se despegaban de la imagen, el peine trabajaba meditativo, la bata abierta dejaba asomar los senos entrecruzados de varias muchachas." 8

En cambio, Macabea encuentra en el espejo la anulación de su identidad

Se miró maquinalmente en el espejo que colgaba sobre el lavabo sucio y desconchado lleno de pelos algo concordante con su vida. Le pareció que el espejo opaco y oscurecido no reflejaba ninguna imagen ¿Acaso se habría esfumado su existencia física? Pero esa ilusión óptica se desvaneció y entrevió la cara deformada por el espejo. ${ }^{9}$

\footnotetext{
${ }^{8}$ LISPECTOR, 2008, p. 41.

${ }^{9}$ LISPECTOR, 2008, p. 25-26.
} 
Macabea se torna invisible en virtud de su fealdad y la escena representa un signo de sumisión a las demandas sociales que instalan un canon de belleza arbitrario. Además se pude señalar que la visión del narrador y del entorno social constituye un remedo de la obra de teatro de Sartre A puerta cerrada: el infierno es la mirada de los otros.

El espejo es una imagen por reflexión, la otredad es un modo de ser espejo del otro. Los personajes de Clarice Lispector manifiestan una imposibilidad de comunicarse con los otros ya que se encuentran inmersos en un proceso de tedio que los abruma.

Diversos autores han caracterizado este impresión de horror al vacío. Baudelaire llamó al tedio ennui y creó para caracterizarlo un termino llamado spleen. Camus trabajo la monotonía infinita que producen los trabajos y los días en El mito de Sísifo, donde el hombre está condenado por siempre a repetir el mismo acto absurdo. También Alberto Moravia representó ese estado en su novela El aburrimiento, describiendo a través de su personaje, el pintor Dino, los patrones que determinan la vida burguesa: contemplar las mismos rostros, repetir los mismos nombres, recorrer los mismos lugares.

Sin embargo, fue Sartre quien mejor caracterizó esa sensación de vació existencial en su novela La náusea. El escritor francés plasmó en el diario de Roquentin el itinerario del hastío pues la novela encarna en clave filosófica la angustia y la responsabilidad que provocan el acto de existir.

En los personajes de Lispector se conjuga una nausea física y emocional, como se verifica en el protagonista de "Desespero e desenlance às tres da tarde".

JB desarrolla una rutinaria vida familiar y está sumido en la indiferencia hacia las personas y las cosas. El cuento detalla la aparición de la náusea y sus consecuencias. La irrupción de ese elemento constituye la respuesta mas radical frente a la alineación del ambiente social. Por ello puede leerse el uso simbólico que adquiere el cuerpo en la narrativa de Lispector: "E a coisa começou: estava com forte náusea e deu-se conta de que precisava urgentemente vomitar. Iniciou-se então uma luta mesquinha e inglória face a face ao terror que começou a dominá-lo."10

El viaje en ómnibus semeja un calvario - esa iconografía se ve confirmada por el sintagma "lagrimas de mártir" y el protagonista acude en forma reiterada a verbos realizativos, "prometeu", "prometía", que desmienten su ateismo.

\footnotetext{
${ }^{10}$ LISPECTOR, 1998, p. 82.
} 
En el cuento, la apelación al silencio provoca un intersticio que agudiza los sentidos y congela el tiempo, provocando expectación en el lector ya que determina el detonante de la náusea.

El relato expande el incidente trivial hasta otorgarle ribetes trágicos planteando la validez de la existencia misma a partir de la pérdida de los documentos en las miasmas de su propio vómito. Por ello, exacerba el tono grotesco y escatológico ofreciendo en tensión lo alto (Goethe - Wagner) en contrapunto con lo más abyecto ("la inmundicia"). El cierre del cuento plantea el reverso de una pesadilla kafkiana pues la metamorfosis del protagonista en virtud de su desfasaje nutricional lo convierte en un hombre libre. Así la conformación de JB está basada sobre una paradoja: exceso y carencia.

Ana Luiza Andrade examina esta representación del cuerpo en los textos clariceanos: "O excesso e a carência - as duas faces disjuntivas de um corpus, das quais uma sempre falta à outra, atuam analogamente às faces disjuntivas gastronômica $\mathrm{e}$ antropofágica, num corpo cultural que se alimenta do outro de si mesmo."11

La protagonista del cuento "Devaneo y embriaguez de una muchacha" se entrega a sentimientos dispersos pues imagina que su vida está abierta a un sinfín de posibilidades.

Devaneo (también empleado en la caracterización de Macabea) significa en su acepción literal delirio, insensatez y constituye el punto de inflexión que modula el deseo de vivir ante la insoportable monotonía de la existencia. En este sentido, opera la alusión María Quiteria como fuga de la realidad. Así, el dinamismo de la fantasía que es recurrente en el texto alcanza una lírica redundancia que sublima el deseo.

Su estado de embriaguez constituye su propia orgía personal y un vehículo de evasión; lograr escapar del ciclo de repeticiones y dejar volar su mente sobre lugares y objetos que la rodean.

El uso del monólogo interior reproduce los mecanismos del pensamiento o bien la asociación de ideas. Lispector utiliza esta técnica para convertir el incidente más trivial o el objeto más común en algo tan apasionante como si fuese contemplado por primera vez.

\footnotetext{
${ }^{11}$ ANDRADE, 1998, p. 134.
} 
En el texto, mediante el flujo de conciencia, el cuerpo de la mujer se transforma por el uso de una animalización en langosta y luego en escorpión.

La crítica ha observado semejanzas entre Clarice Lispector y Virginia Wolf respecto al uso de esta técnica. Sin embargo, si releemos la novela de la escritora inglesa La señora Dalloway, advertimos que en sus monólogos sus frases suenan "demasiado literarias" y adolecen de artificiosidad. Por el contrario, la escritura de Lispector capta con naturalidad la irrupción de lo maravilloso en lo cotidiano y por ello transmite con singular eficacia esa sensación de inmediatez al lector.

El personaje del cuento habita en un estado de insatisfacción que se percibe en el distanciamiento entre el adentro (su propia subjetividad) y el afuera (las pautas que impone la vida social).

El mundo exterior representado en el restaurante es una zona plagada por la futilidad mundana y la incomunicación. Por ello la protagonista establece un dialogo consigo misma expresando sus pensamientos más recónditos.

También el monopolio de la visón, pues la mirada sustenta el fluir de la experiencia, le permite detectar a los seres anodinos que pueblan las mesas y a rivales amenazantes como la muchacha que opera como mecanismo especular para interrogar la propia existencia.

Por ello, el largo escrutinio sobre la joven revela al sujeto narcisista que se ve a si mismo en otros o a la inversa toma al otro por si mismo.

El acto de mirar precede a la nausea que produce una culpa existencial que hace recapacitar sobre la existencia.

Miraba alrededor, paciente obediente. Ay palabras, palabras objetos de habitación alineados en orden de palabras formando aquellas frases turbias y aburridas, que quien sepa leer, leerá. Aburrimiento, aburrimiento, ay que fastidio. Que pesadez... Ay me da una cosa tan rara que ni sé siquiera como explicarla... desilusionada, resignada harta de comida, casada contenta con una vaga náusea. ${ }^{12}$

El torbellino de ideas dura un instante y es el conducto de la náusea que desemboca en una epifanía que descubre lo cotidiano ya que la protagonista replantea los significantes que marcan su vida: marido, hijos, hogar. El relato se corta en el flujo de conciencia final proponiendo una estética de lo inacabado en desmedro de la

\footnotetext{
${ }^{12}$ LISPECTOR, 2008, p. 48.
} 
consumación. Así, se despliega un texto pletórico de sugerencias ante un desenlace que nunca llega.

Macabea encarna la actitud de quien siente náusea ante el mero hecho de existir. Sus vagabundeos resaltan el anonimato, la humillación y la soledad. Esa atmósfera de desencanto se traduce de varias maneras.

Los motivos se establecen en la melancolía que produce el día domingo (fenómeno común a la protagonista de "Devaneo y embriaguez de una muchacha"). En la nausea corporal fruto del recuerdo de haber ingerido un gato frito y en lo esencial en la insatisfacción recurrente que experimenta. Y estalla en el momento de la muerte: "En esta hora exacta Macabea tuvo una náusea profunda y casi vomitó, quería vomitar lo que no es su cuerpo, vomitar algo luminoso. Una estrella de mil puntas."13

Para los personajes clariceanos el paisaje exterior no varia, mientras ellos permanecen la mayor parte del tiempo rumiando su insatisfacción y su soledad. Entre el fárrago de palabras que transmite el texto y los silencios certeros de los protagonistas, se instaura el discreto encanto de la ambigüedad. Por ello, debemos leer entre líneas para confirmar toda la precariedad de su existencia.

Lo cotidiano incuba el aburrimiento por eso, desean apropiarse del instante que los redima.

Se ha señalado que la literatura de Clarice Lispector es una crónica del instante que capta, manipula, congela y transforma en un acontecimiento. La música, un gesto, una sensación corporal plasman esa búsqueda. Sus relatos cuentan un mínimo de peripecias, los hechos suelen ser banales pero plantean una pregunta crucial ¿Cómo representar el deseo en la modernidad?

La tematización del deseo como productor de textualidad es recurrente en su obra. Ese espacio que se instala con intensidad, pero como deseo inconcluso nos sugiere una analogía con uno de los más grandes directores de cine del siglo XX: Andrei Tarkoski.

Como en sus películas Solaris y Stalker (La zona), los espacios clariceanos representan una paradoja: sucede todo y no sucede nada. En un mundo hostil sometido a reglas inflexibles y en un mundo benjaminiano donde la experiencia es cuestionada, existe un umbral que puede cumplir nuestras aspiraciones más secretas.

${ }^{13}$ Idem, p. 80 . 
Su literatura puede se leída como una ráfaga que refleja ese territorio de incertidumbre donde reina ese vacío, esa carencia, ese anhelo insatisfecho, esa fantasía fugaz y que sin embargo, siempre ofrece una tregua poética que conjura al lector. 


\section{REFERÊNCIAS}

ANDRADE, Ana Luiza. Políticas indigestas gastronomia e antropofagia. Travessia, Florianópolis, n. 36, jun. 1998

BARTHES, Roland. El susurro del lenguaje. Barcelona: Paidós, 1987.

BENJAMIN, Walter. La obra de arte en la época de su reproductibilidad técnica. In: Discursos interrumpidos. Madrid: Taurus, 1982. p. 47.

FOUCAULT, Michel. ¿Que es un autor? Dialéctica, n. 16, año IX, 2002.

FRANCO, Jean. Marcar diferencias, cruzar fronteras. Chile: Ed. Cuarto Propio, 1996.

LISPECTOR, Clarice. La hora de la estrella. Madrid: Siruela, 2000.

Cuentos reunidos. Madrid: Siruela, 2008. 1998.

. Desespero e desenlace as tres da tarde. Travessia, Florianópolis, n. 36, jun.

SARTRE, Jean Paul. La náusea. Buenos Aires: Losada, 1947. 